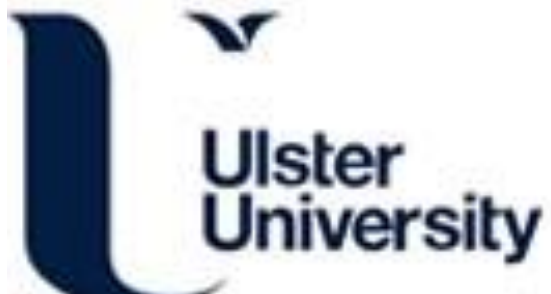

\section{Proteomic analysis of circulating immune complexes in juvenile idiopathic arthritis reveals disease-associated proteins}

\author{
Low, J. M., Chauhan, A. K., Gibson, D. S., Zhu, M., Chen, S., Rooney, M. E., Ombrello, M. J., \& Moore, T. L. \\ (2009). Proteomic analysis of circulating immune complexes in juvenile idiopathic arthritis reveals disease- \\ associated proteins. PROTEOMICS - Clinical Applications, 3(7), 829-840. \\ https://doi.org/10.1002/prca.200800073
}

Link to publication record in Ulster University Research Portal

Published in:

PROTEOMICS - Clinical Applications

Publication Status:

Published (in print/issue): 09/07/2009

DOI:

10.1002/prca.200800073

Document Version

Publisher's PDF, also known as Version of record

\section{General rights}

Copyright for the publications made accessible via Ulster University's Research Portal is retained by the author(s) and / or other copyright owners and it is a condition of accessing these publications that users recognise and abide by the legal requirements associated with these rights.

\section{Take down policy}

The Research Portal is Ulster University's institutional repository that provides access to Ulster's research outputs. Every effort has been made to ensure that content in the Research Portal does not infringe any person's rights, or applicable UK laws. If you discover content in the Research Portal that you believe breaches copyright or violates any law, please contact pure-support@ulster.ac.uk. 


\title{
Proteomic analysis of circulating immune complexes in juvenile idiopathic arthritis reveals disease-associated proteins
}

\author{
Jason M. Low ${ }^{1,2}$, Anil K. Chauhan ${ }^{2,3}$, David S. Gibson ${ }^{4}$, Mengmeng Zhu $^{5}$, Sixue Chen ${ }^{5}$, \\ Madeleine E. Rooney ${ }^{4}$, Michael J. Ombrello ${ }^{2}$ and Terry L. Moore ${ }^{1,2}$ \\ ${ }^{1}$ Department of Molecular Microbiology and Immunology, Saint Louis University School of Medicine, \\ Saint Louis, MO, USA \\ 2 Division of Rheumatology, Saint Louis University School of Medicine, Saint Louis, MO, USA \\ ${ }^{3}$ ProGen Biologics, LLC, Saint Louis, MO, USA \\ ${ }^{4}$ Arthritis Research Group, Musculoskeletal Education and Research Unit, Musgrave Park Hospital, \\ Queen's University, Belfast, UK \\ ${ }^{5}$ Department of Botany, University of Florida, Gainesville, FL, USA
}

Juvenile idiopathic arthritis reflects a group of clinically heterogeneous arthritides hallmarked by elevated concentrations of circulating immune complexes. In this study, the circulating immune complex proteome was examined to elucidate disease-associated proteins that are overexpressed in patients with an aggressive, and at times destructive, disease phenotype. To solve this proteome, circulating immune complexes were isolated from the sera of patients with chronic, erosive or early-onset, aggressive disease and from patients in medical remission or healthy controls subsequent to protein separation by 2-DE. Thirty-seven protein spots were overexpressed in the circulating immune complexes of the aggressive disease groups as compared to controls, 28 of which have been confidently identified to date. Proteolytic fragments of glyceraldehyde-3-phosphate dehydrogenase, serotransferrin, and $\alpha$-1-antitrypsin have been identified among others. In total, these 28 putative disease-associated proteins most definitely contribute to immune complex formation and likely have a significant role in disease etiology and pathogenesis. Moreover, these proteins represent markers of aggressive disease, which could aid in diagnosis and management strategies, and potential therapeutic targets to prevent or control disease outcome. This is the first in-depth analysis of the circulating immune complex proteome in juvenile idiopathic arthritis.

\section{Keywords:}

Circulating immune complexes / Disease / Juvenile idiopathic arthritis / Mass spectrometry

\author{
Correspondence: Dr. Terry L. Moore, Director, Division of Adult \\ and Pediatric Rheumatology, Room 213A, Doisy Hall, 1402 South \\ Grand Blvd., Saint Louis, MO 63104, USA \\ E-mail: mooretl@slu.edu \\ Fax: +1-314-977-8818
}

\begin{abstract}
Abbreviations: $\alpha-1 \mathrm{AT}$, alpha-1-antitrypsin; CE, chronic, erosive; CIC, circulating immune complex; EOA, early-onset, aggressive; GAPDH, glyceraldehyde-3-phosphate dehydrogenase; GPI, glucose-6-phosphate isomerase; JIA, juvenile idiopathic arthritis; MR, medical remission; PCNA, proliferating cell nuclear antigen; RA, rheumatoid arthritis; RF, rheumatoid factor; SF, synovial fluid; SLE, systemic lupus erythematosus; TNF, tumor necrosis factor
\end{abstract}

Received: March 13, 2008 Revised: January 13, 2009 Accepted: January 26, 2009

\section{Introduction}

Juvenile idiopathic arthritis (JIA) describes a clinically heterogeneous group of arthritides which begin before 16 years of age, persist for more than six weeks, and are of unknown etiology [1-3]. Several disease subtypes comprise JIA, each having distinct methods of presentation, clinical signs and symptoms, and genetic backgrounds (for certain subtypes). Of the seven disease subtypes, rheumatoid factorpositive $\left(\mathrm{RF}^{+}\right)$polyarthritis has the greatest risk for poor disease outcome $[4,5]$ and least favorable spontaneous remission rates [6]. Moreover, this JIA subtype is char- 
acterized by progressive and diffuse joint involvement with early changes such as joint space narrowing, decrease in carpal length, ankylosis, erosions, and subluxation. Severe deforming arthritis is commonly observed five years from onset [7].

Even though the etiology and pathogenesis of JIA are unclear, a role for elevated concentrations of pathogenic circulating immune complexes (CICs) has been clearly established [3, 8-17]. The formation of transient CICs represents a normal physiological response to an antigen, but persistent, elevated concentrations of CICs result in defective removal and subsequent tissue deposition [18]. Several attempts have been made to identify proteins in CICs from both adult rheumatoid arthritis (RA) and JIA patients by various methods; however, protein identities were inconclusive and based on molecular weight information alone [8, 19]. Moreover, only a limited number of approaches were used to characterize CICs for potential antigens/antibodies; the most common method being immunoprecipitation followed by SDS-PAGE and immunoblotting (for review see references [8, 19-27]). The lack of an effective method for efficient CIC isolation and the relatively low concentrations of antigen in CICs contribute to the difficulties in their identification. Recent attempts to identify disease-associated proteins have been restricted to the analysis of whole biologic fluid; for example, serum, synovial fluid (SF), urine, and cerebrospinal fluid [28-34]. However, analysis of these fluids pose limitations to studying disease-associated proteins because of the wide dynamic range of proteins and abundance of common proteins in complex biological samples. These limitations, in part, explain the inability to discover low abundance serum proteins [35-37]. A more focused approach would be to deconstruct CICs as the key contributors to pathology. The characterization of CICs, in addition to whole fluid, could potentially corroborate findings or resolve issues regarding a disease-associated protein's role in the disease process. Moreover, CIC analysis may provide differential expression patterns of disease-specific proteins and key posttranslational modification(s) that elicit the initial autoimmune response by reducing the dynamic range of high abundance proteins and increasing the sensitivity of detection [38]. To purify CICs from biological fluids, in relatively large amounts, and further study the differentially expressed proteins by MS analysis would significantly enhance our ability to identify disease markers. The development of such processes would also identify posttranslational modifications that are fundamental to disease pathogenicity. The formation of CICs represents early immune responses and hence directly contributes to disease pathogenesis in JIA. Therefore, proteomic analysis of CICs would yield more insight into the disease process.

With the advent of modern proteomic methods, namely 2-DE coupled with MS, the opportunity to characterize complex protein profiles has made identifying diseaseassociated proteins a reality. While 2-DE and LC MS/MS are not well-suited for high-throughput screening, they are ideal methods for deconstructing complex protein mixtures like CICs in search of disease-associated proteins and potential autoantigens [39]. In this study, we use a novel CIC isolation technique, 2-DE, and nanoflow HPLC-MS/MS to identify disease-associated proteins in CICs isolated from patients with an unremitting and erosive phenotype of $\mathrm{RF}^{+}$polyarticular JIA. These proteins represent markers of aggressive disease and potential therapeutic targets to prevent or control disease outcome. This report is the first detailed analysis of a CIC proteome from patients with JIA.

Table 1. Clinical and demographic characteristics of the study subjects

\begin{tabular}{lllll}
\hline Disease subtype & CE & EOA & MR & Healthy \\
\hline Total number & 3 & 5 & 6 & 4 \\
Age (years) & $22.5 \pm 2$ & $14.6 \pm 5.6$ & $17.2 \pm 5.7$ & $22.4 \pm 3.4$ \\
Male/female (n) & $0 / 3$ & $0 / 5$ & $0 / 6$ & $0 / 4$ \\
Disease duration (years) & $10.9 \pm 3.8$ & $1.3 \pm 1.3$ & $7 \pm 7.4$ & $\mathrm{n} / \mathrm{a}$ \\
Swollen joint count $(n)$ & $19.3 \pm 7.6$ & $20.8 \pm 6.4$ & $7.3 \pm 8.6$ & 0 \\
Tender joint count $(n)$ & $4.3 \pm 6.7$ & $11.8 \pm 6.9$ & $0.3 \pm 0.5$ & 0 \\
Erosions/JSN (n) & $3 / 3$ & $1 / 1$ & $2 / 3$ & $0.3 \pm 0.2$ \\
CRP (mg/dL) & $2.7 \pm 2.8$ & $2.5 \pm 2$ & $0.8 \pm 4.4$ & $\mathrm{n} / \mathrm{a}$ \\
ESR (mm/h) & $90 \pm 34.8$ & $36 \pm 26.1$ & $6 / 0$ & $0 / 4$ \\
RF $(P / N)$ & $3 / 0$ & $5 / 0$ & $2 / 4$ & $0 / 4$ \\
Anti-CCP $(P / N)$ & $3 / 0$ & $3 / 2$ & $6 / 0$ & $0 / 4$ \\
DMARD (yes/no) & $3 / 0$ & $0 / 5$ & $6 / 0$ & $0 / 4$ \\
NSAID (yes/no) & $3 / 0$ & $0 / 5$ & $3 / 3$ & $0 / 4$ \\
Biologic (yes/no) & $3 / 0$ & $0 / 5$ & \\
\hline
\end{tabular}

Values are the mean ( \pm standard deviation) or the number of subjects. n/a, not applicable or not determined; JSN, joint space narrowing; CRP, C-reactive protein; ESR, erythrocyte sedimentation rate; RF, rheumatoid factor; anti-CCP, anti-CCP antibodies; DMARD, disease modifying antirheumatic drug; NSAID, nonsteroidal antiinflammatory drug; $P$, positive; $N$, negative. 


\section{Materials and methods}

\subsection{Patient and serum samples}

Patient and healthy donor sera were collected from the outpatient clinics of the Saint Louis University Medical Center and Cardinal Glennon Children's Hospital in Saint Louis, Missouri. A total of eight JIA sera were collected from patients with $\mathrm{RF}^{+}$polyarthritis according to ACR criteria [3], three with chronic, erosive (CE) and five with an early onset, aggressive (EOA) phenotype (Table 1). In addition, we evaluated six $\mathrm{RF}^{+}$polyarticular JIA patients in medical remission (MR), and four age- and sex-matched healthy controls. Patients in MR were defined as being asymptomatic with no active synovitis and normalized inflammatory mediators. Healthy controls were defined as having normal laboratory values and no clinical evidence of disease. Serum samples were aliquoted and stored at $-80^{\circ} \mathrm{C}$ until isolation of CICs by affinity chromatography. The study was approved by the Institutional Review Board of the Saint Louis University Medical Center.

\subsection{Isolation of $\mathrm{CICs}$}

Prior to affinity chromatography, serum samples were thawed and kept in a $37^{\circ} \mathrm{C}$ water bath for $10 \mathrm{~min}$ followed by centrifugation at $7000 \times \mathrm{g}$ for $10 \mathrm{~min}$. CICs from the clear serum supernatant were adsorbed by passing $3 \mathrm{~mL}$ of serum diluted with $1: 1$ with $1 \times$ PBS over $2 \mathrm{~mL}$ of Proceptor ${ }^{\mathrm{TM}}$. conjugated 4B-FF sepharose resin (ProGen Biologics, Wildwood, MO) [40]. After sample adsorption, the resin was washed with five column volumes of $1 \times$ PBS followed by one column volume of $500 \mathrm{mM} \mathrm{NaCl}$ solution to remove any nonspecifically bonded material. A final wash with 15 column volumes of $1 \times$ PBS was applied until the eluate showed no absorbance at $280 \mathrm{~nm}$. The bound material was eluted using three $\mathrm{ml}$ of $0.1 \mathrm{M}$ glycine$\mathrm{HCl}$ buffer ( $\mathrm{pH}$ 3.5) and immediately neutralized with $0.5 \mathrm{~mL}$ of $1 \mathrm{M}$ Tris- $\mathrm{HCl}$ ( $\mathrm{pH} 7.5$ ). This eluate was concentrated to a final volume of $200 \mu \mathrm{L}$ with Amicon Ultra $5 \mathrm{kDa}$ molecular weight cutoff centrifugal filter devices (Millipore, Billerica, MA). The buffer exchange was completed in these filters with $10 \mathrm{mM}$ Tris- $\mathrm{HCl}(\mathrm{pH} 7.5)$. Protein concentrations between 100 and $200 \mu \mathrm{g} / \mathrm{mL}$ were determined by micro BCA protein assay (Pierce, Rockford, IL) and $20 \mu \mathrm{L}$ aliquots were stored at $-80^{\circ} \mathrm{C}$ for further use. The specificity of the interaction between $\mathrm{CICs}$ and Proceptor $^{\mathrm{TM}}$ conjugated resin, and nonspecific interaction between serum proteins and uncoupled resin, was confirmed by denaturing SDS-PAGE analysis and silver staining (Supporting Information Figs. 1 and 2). Moreover, serial analysis of multiple individual serum samples by Proceptor $^{\mathrm{TM}}$ ELISA substantiated the minimal loss of CICs by precipitation during sample preparation or storage (data not shown).

\section{$2.32-D E$}

2-DE was performed at $20^{\circ} \mathrm{C}$ with a Bio-Rad Protean IEF Cell system, a Criterion gel rig and associated power supply, $11 \mathrm{~cm}$ IPG Ready Strips (pH 3-10 linear), 10\% bis-tris Criterion XT precast gels, and reagents according to the manufacturer's guidelines (Bio-Rad Laboratories, Hercules, CA). Briefly, a CIC concentration of $10 \mu \mathrm{g}$ was made up to a total volume of $185 \mu \mathrm{L}$ in sample rehydration buffer $(8 \mathrm{M}$ urea, $2 \mathrm{M}$ thiourea, $2 \%$ CHAPS, 2\% SB3-10, 20 mM DTT, 2\% $\beta$-octylglucoside, $40 \mathrm{mM}$ Tris, $0.2 \%$ Bio-Lyte 3/10 ampholyte, and 0.001\% bromophenol blue). Each sample was applied to a linear $\mathrm{pH}$ 3-10 IPG strip and passively rehydrated for $16 \mathrm{~h}$ at room temperature prior to IEF, in accordance with manufacturer's recommendations. The first dimension separation of proteins by IEF was performed in duplicate $(n=2)$. A total of 30000 Vh were applied during IEF. After IEF, the strips were removed, rinsed in excess $18.2 \mathrm{M} \Omega \mathrm{H}_{2} \mathrm{O}$, and equilibrated in $2 \mathrm{~mL}$ of buffer containing $6 \mathrm{M}$ urea, $0.375 \mathrm{M}$ Tris- $\mathrm{HCl}$ buffer (pH 8.8), 2\% SDS, $20 \%$ glycerol, and $2 \%$ (w/v) DTT for $15 \mathrm{~min}$ with continuous shaking. After the first incubation, the IEF strips were incubated for another $15 \mathrm{~min}$, with continuous shaking, at room temperature in a similar buffer, substituting $2.5 \%(\mathrm{w} / \mathrm{v})$ iodoacetamide for $2 \%(\mathrm{w} / \mathrm{v})$ DTT. Postequilibration, IPG strips were laid into single well $10 \%$ bis-tris Criterion gels and sealed in with $0.5 \%$ agarose $(\mathrm{w} / \mathrm{v})$. Five microliter of broad range SDS-PAGE molecular weight standards (Bio-Rad Laboratories) were used per gel. The second dimension separation was achieved with denaturing SDS-PAGE run at $175 \mathrm{~V}$ for $1.5 \mathrm{~h}$. Following 2-DE, gels were stained overnight with Sypro Ruby (Molecular Probes, Eugene, OR) according to manufacturer's recommendations.

\subsection{Image and statistical analysis}

Protein spots were visualized using GelPix (Genetix, New Milton, UK). Gels were scanned as 16-bit gray scale Tif image files and protein spot analysis was performed with Progenesis Samespots version 2.0 build 2644.18003 software (Nonlinear Dynamics, Newcastle upon Tyne, UK) comprising gel warping, normalization, and comparison modules. Briefly, a single reference gel was assigned as the gel image with the most clearly resolved spots detected and all remaining gel images were aligned to this reference. The same spot outlines were overlaid onto all images, ensuring no data was omitted at this early stage. Landmark spots were used to confirm spot matching across all gels and three-dimensional "peaks" were used to verify spot assignment. The protein spots in each image were automatically linked between the individual gel images for each patient. The Samespots software performs $\log$ transformation of the spot volume ratios to generate normally distributed data. Log normalized volume was used in quantifying differential expression. Intrasample variance of spot volumes within each group was accounted for and outlying values were not included in this study. 
Matched and volumes normalized within replicate sample sets were used to create "master" gels for each patient or group, from the series of CIC samples. Subsequent qualitative subtraction of one patient group "master" gel from another revealed a population of proteins uniquely expressed in the CICs of that particular patient group. Qualitative differential spot analysis was performed on "master" gels from two combined groups (combined disease group versus combined MR/healthy group). Pairwise comparisons were made to establish patient group-patient group variations. Within the Samespots review module, each comparison was filtered to find the spots (i) with a significant difference in their expression pattern ( $p \leq 0.05$ for the unpaired $T$-test) and (ii) having a two-fold or greater change in protein spot expression between the two groups. Fold change was calculated as the ratio of the average log normalized volume between the two groups. Results from an independent sample T-test (SPSS v.15, Chicago, IL) for comparisons of individual spot volumes between groups prior to $\log$ normalization are listed in Supporting Information Table 1.

\subsection{Cluster analysis}

Quantitative data sets were analyzed using Epclust (http:// www.bioinf.ebc.ee/EP/EP/EPCLUST/), a generic data clustering, visualization, and analysis tool for genomic or proteomic expression data. Hierarchal cluster analysis allows samples with interindividual protein expression patterns that are highly similar to be reordered in an agglomerative fashion, using the unweighted pair-group method with arithmetic mean clustering procedure. In this method, the distance between two clusters is calculated as the average distance between all pairs of objects in the two different clusters. Euclidean distance was the similarity
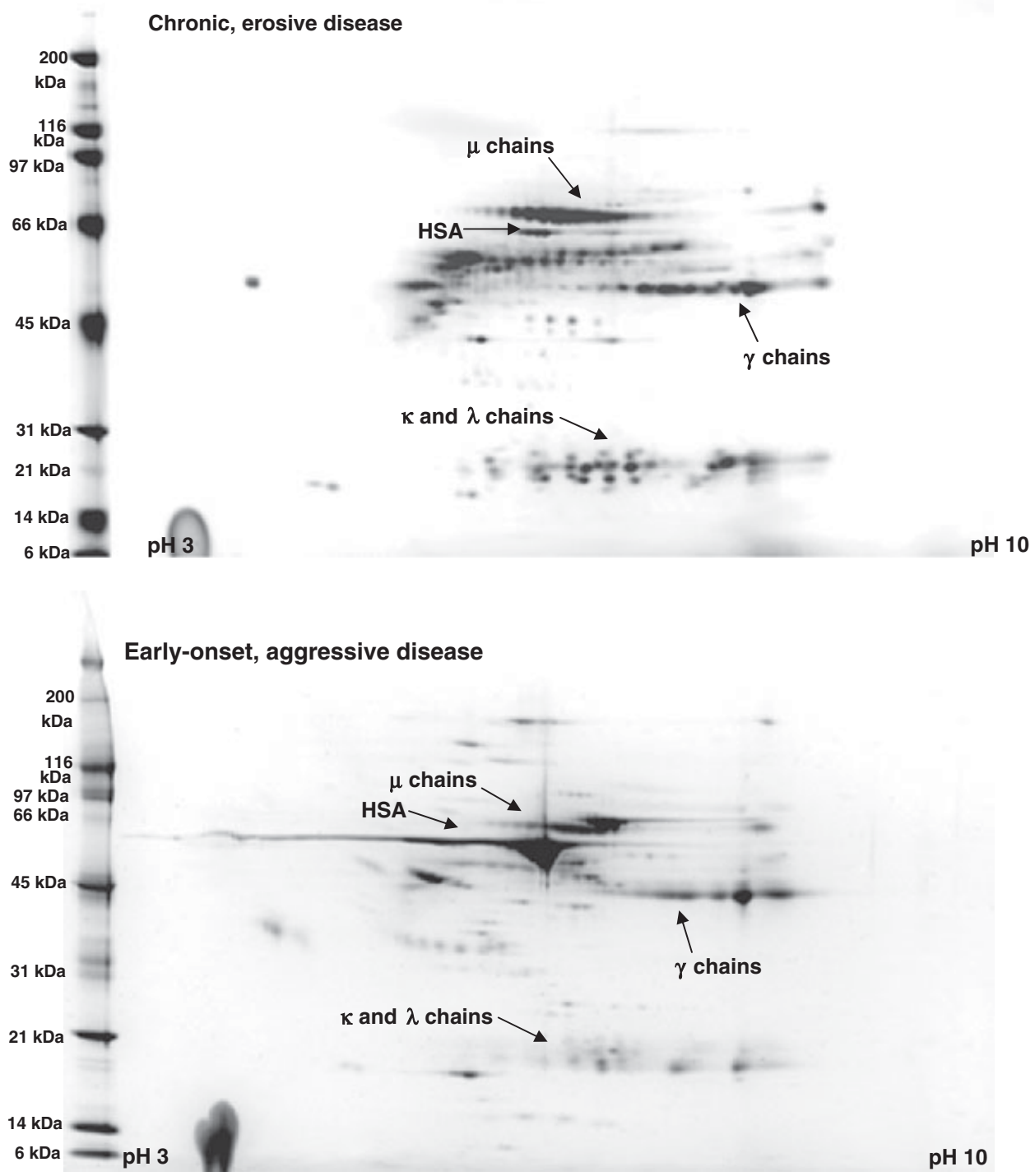

Figure 1. Isolation of the aggressive JIA CIC proteome. Representative 2-DE reveals $\sim 455$ protein spots per gel $(\mathrm{pH}$ range 5-9) for $\mathrm{ClCs}$ of JIA patients with an aggressive phenotype. Representative 2-DE of $\mathrm{CICs}$ from MR and healthy groups are shown in Supporting Information Fig. 1. HSA, human serum albumin. 
measure used to group or separate the expression data. The grouping of protein expression levels is presented in the form of heat map accompanied by dendrograms with trees and branches depicting the extent of similarity between the different groups in the samples.

\subsection{Protein spot extraction and identification}

Protein spots were excised using Gelpix (Genetix) and subjected to in-gel trypsin digestion and the eluted peptides were subjected to nanoflow HPLC-MS/MS analysis using an ABI quadrupole time-of-flight (QSTAR XL) MS/MS system (Applied Biosystems, Foster City, CA), as previously described [41, 42]. Peptide identifications were achieved using the IPI human (67524 entries, July 8, 2007) [43] and NCBI nonredundant (NCBInr) databases (5 222402 entries, July 2, 2007) with the Mascot 2.0 search engine (Matrix Science, Boston, MA). The constraints used were (i) tryptic peptides with up to one missed cleavage site and (ii) $0.3 \mathrm{Da}$ mass tolerances for both MS and MS/MS fragment ions. The charge states of precursor ions selected were 1-3. Oxidation of methionine and N-terminal deamidation were specified as variable modifications and carbamidomethylation of cysteine as a fixed modification, respectively. Unambiguous identification was judged by the criteria reported previously [42].

\section{Results}

\subsection{Establishment of a JIA CIC proteome}

As compared to the magnitude of the human plasma proteome (http://ca.expasy.org/swiss-2dpage/map = plasma_human), we have demonstrated a preliminary method to establish a refined CIC proteome for JIA patients with an aggressive phenotype. Results of 2-DE from the CE, EOA, MR, and healthy groups revealed that the majority of proteins from CICs migrated within the $\mathrm{pH}$ 5-9 range (Fig. 1; MR and healthy are shown in Supporting Information Fig. 1). Using comparative analysis of results from the National Biomedical Research Foundation (NBRF) protein database, we established the presence of IgM and IgG heavy chains, $\kappa$ and $\lambda$ light chains, and HSA. These identities were previously confirmed by MALDI-TOF analysis of protein spots from systemic lupus erythematosus (SLE) CIC 2-DE gels [41]. We determined intra- and intersample variability in protein concentration by analyzing changes in spot intensity over replicate 2-DE gels, per sample. Visual inspection of replicate sets indicated that protein spot coordinates $(\mathrm{pI} / \mathrm{MW})$ and intensities were similar between gels run from the same sample, but significant differences were noted between patient's and, more importantly, between groups.

Initially, 1019 "spots" were detected with 1.1-fold or more difference between gels. After further review of spot quality, software recognition algorithm resulted in spot editing that increased the net number of detected spots to 1150 "spots". From here, approximately 455 true protein spots were retained for comparison across individuals and patient groups. The remaining 695 "spots" were rejected because of nonspot features such as being elongated and having poor resolution. A threshold of two-fold or greater difference between protein expression patterns was set to further filter out less significant spots. Normalized spot volume comparisons of groups CE, EOA, and MR to healthy controls revealed interesting trends in protein expression patterns (Supporting Information Fig. 2). When comparing the CE group to healthy controls, 61 proteins showed twofold or greater increased levels while 58 proteins showed a

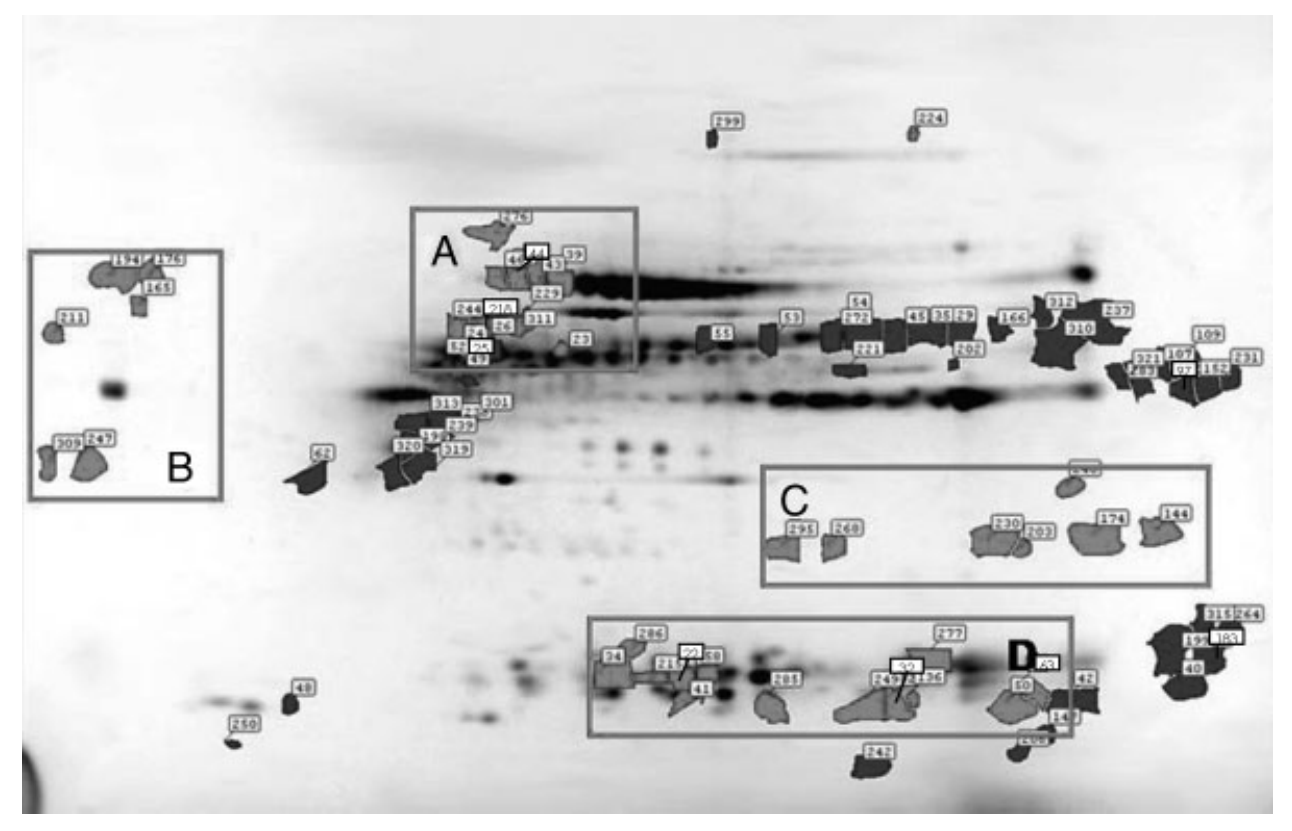

Figure 2. Normalized spot volume comparisons of the CE/EOA combined disease group to $\mathrm{MR} /$ healthy combined control group. Samespots analysis reveals 37 protein spots with increased expression (gray) and 45 protein spots with decreased expression (black) in the $\mathrm{CICs}$ of the CE/EOA combined disease group as compared with MR/ healthy combined control group. Differential expression patterns are two-fold or greater and significant, $p \leq 0.05$, for the unpaired $T$-test. 

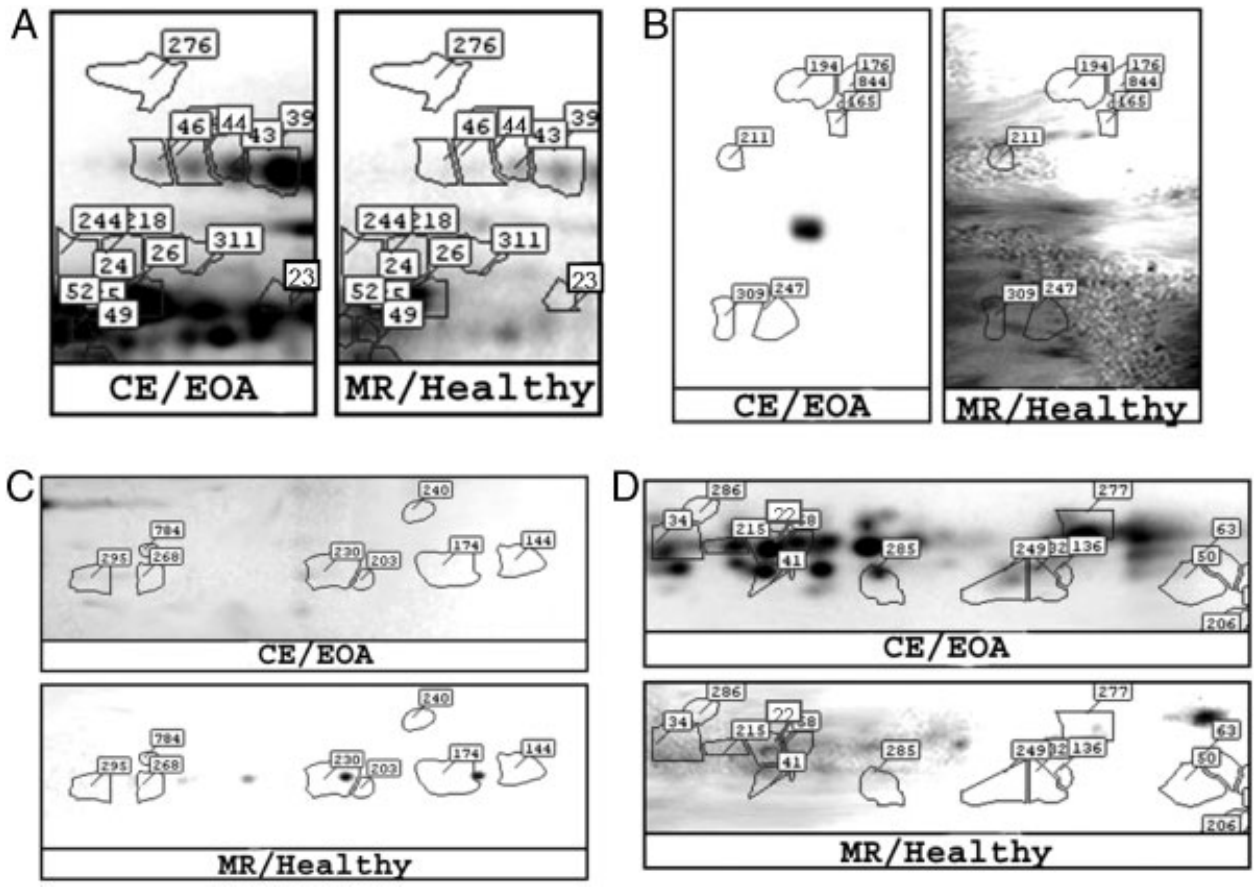

Figure 3. Putative diseaseassociated proteins highlighted in regions $A-D$. Protein spots within regions A-D from Fig. 2 were picked and analyzed by nanoflow HPLC-MS/MS. CE, chronic, erosive; EOA, early onset, aggressive; MR, medical remission.

\section{Individual $\mathrm{CIC}$}

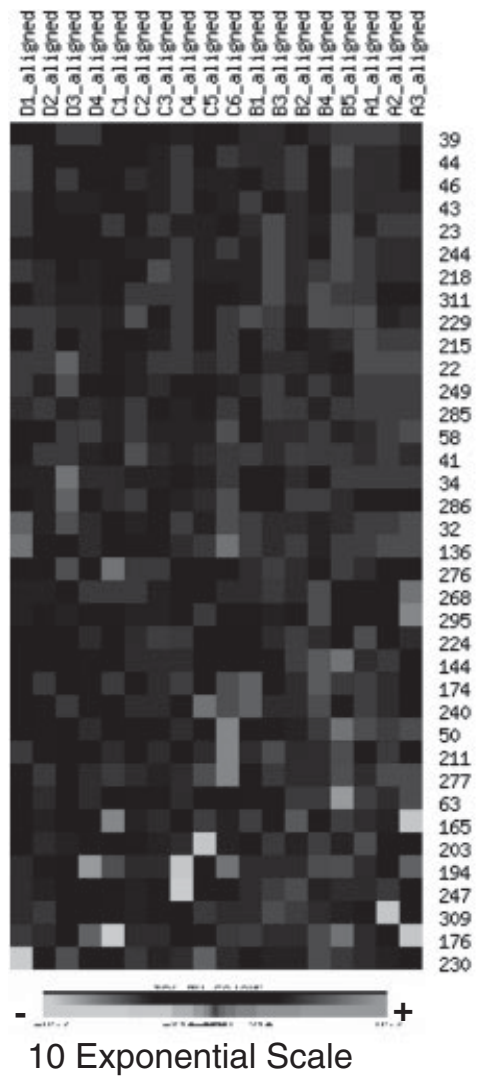

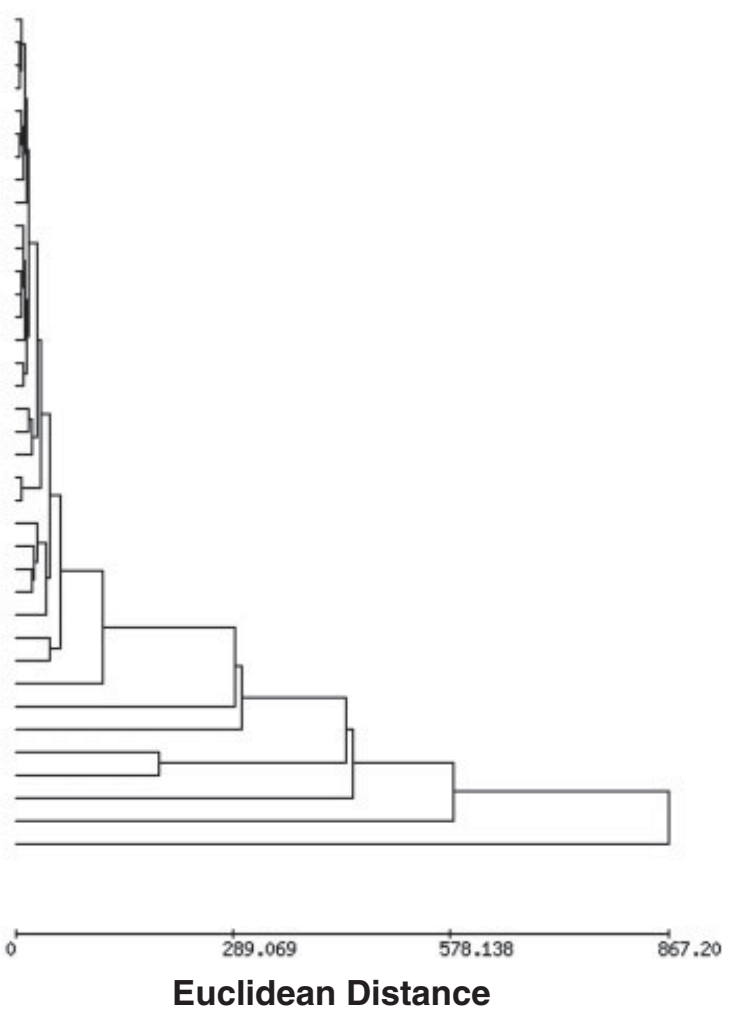

Figure 4. Hierarchal cluster analysis reveals trends in disease-associated protein expression. Quantitative data sets showing fold differences in protein expression were analyzed using Epclust. Subsequent hierarchal cluster analysis allows samples with interindividual protein expression patterns that are highly similar to be reordered into clusters of similarity. The list of differentially expressed proteins was generated using a cut-off of two-fold or greater expression difference and $T$-test with $p \leq 0.05$. Euclidean distance is the measure of similarity between two clusters, calculated as the average distance between all pairs of objects in the two different clusters. Individual protein spots are labeled on the vertical axis. Patient's individual CIC proteomes are labeled on the horizontal axis of the heat map: CE, A1-3; EOA, B1-5; MR C1-6, and Healthy, D1-4. The $e^{10}$ scale represents varying degrees of increased protein and decreased protein expression. 
two-fold or greater decrease in expression (Supporting Information Fig. 2A). Moreover, the EOA group displayed 77 proteins with two-fold or greater expression while 63 proteins had two-fold or greater decrease as compared to healthy controls (Supporting Information 2B). Finally, when comparing the protein expression profiles of the MR and healthy groups, the MR group had 43 proteins with a twofold or greater increase in spot intensity and 21 proteins with a two-fold or greater decrease (Supporting Information Fig. 2C).

Table 2. Identification and quantification of disease-associated proteins

\begin{tabular}{|c|c|c|c|c|c|c|c|}
\hline Spot ID & Protein ID & $\begin{array}{l}\text { MOWSE } \\
\text { score }\end{array}$ & $\begin{array}{l}\text { Peptides } \\
\text { matched }\end{array}$ & Accession & $\mathrm{p} /$ & $\begin{array}{l}\mathrm{MW} \\
(\mathrm{kDa})\end{array}$ & $\begin{array}{l}\text { Fold change in CE and } \\
\text { EOA disease }\end{array}$ \\
\hline Marker & Glycogen phosphorylase b & 467 & 16 & gi231300 & 6.6 & 95.8 & $\mathrm{~N} / \mathrm{A}$ \\
\hline \multicolumn{8}{|c|}{ Region A } \\
\hline 23 & Not identified & & & & 6.9 & 57.6 & 4.5 \\
\hline 39 & IGHM protein & 182 & 14 & IPI00479708 & 6.9 & 69.3 & 3.1 \\
\hline $43 / 46$ & $\begin{array}{l}\text { Ig mu heavy chain disease } \\
\text { protein }\end{array}$ & $88 / 139$ & $6 / 6$ & IPI00385264 & 5.1 & 43.5 & $2.9 / 3.0$ \\
\hline 44 & IGHM protein & 233 & 9 & IPI00477090 & 5.9 & 68.1 & 2.9 \\
\hline $218 / 244$ & $\begin{array}{l}\text { SERPINA1 } \alpha \text {-1-antitrypsin } \\
\text { precursor }\end{array}$ & $139 / 206$ & $7 / 6$ & IPI00553177 & 5.4 & 46.9 & $3.5 / 3.1$ \\
\hline 229 & $\begin{array}{l}\text { ALB uncharacterized protein } \\
\text { ALB }\end{array}$ & 70 & 5 & IPI00022434 & 6.3 & 73.8 & 2.9 \\
\hline 276 & TF serotransferrin precursor & 183 & 7 & IPI00022463 & 6.8 & 79.3 & 2.7 \\
\hline 311 & $\begin{array}{l}\text { ALB isoform } 1 \text { of serum } \\
\text { albumin precursor }\end{array}$ & 61 & 10 & IPI00745872 & 5.9 & 71.3 & 2.6 \\
\hline \multicolumn{8}{|l|}{ Region B } \\
\hline $165 / 176$ & Not identified & & & & $3.7 / 4$ & $64.5 / 72.1$ & $4.6 / 3.2$ \\
\hline $194 / 211$ & Not identified & & & & $3.5 / 3.3$ & $68.7 / 61.5$ & 2.9/3.2 \\
\hline $247 / 309$ & Not identified & & & & $3.4 / 3.2$ & $47.8 / 44.6$ & $3.1 / 2.5$ \\
\hline \multicolumn{8}{|c|}{ Region C } \\
\hline $144 / 174$ & $\begin{array}{l}\text { Glyceraldehyde-3-phosphate } \\
\text { dehydrogenase }\end{array}$ & $139 / 181$ & $6 / 7$ & IPI00219018 & 8.6 & 36.2 & $3.5 / 3.2$ \\
\hline $203 / 230$ & $\begin{array}{l}\text { Glyceraldehyde-3-phosphate } \\
\text { dehydrogenase }\end{array}$ & $106 / 119$ & $7 / 8$ & IPI00219018 & 8.6 & 36.2 & $2.9 / 2.4$ \\
\hline 240 & $\begin{array}{l}\text { IGHG2 Putative unchara- } \\
\text { cterized protein }\end{array}$ & 87 & 7 & IPI00399007 & 7.6 & 46.7 & 2.7 \\
\hline & DKFZp686I04196 (fragment) & & & & & & \\
\hline 268 & $\begin{array}{l}\lg \gamma-2 \text { chain } C \text { region } \\
\text { (fragment) }\end{array}$ & 58 & 5 & IPI00399007 & 7.7 & 36.5 & 2.3 \\
\hline 295 & $\begin{array}{l}\text { ALB uncharacterized protein } \\
\text { ALB }\end{array}$ & 61 & 1 & IPI00022434 & 6.3 & 73.8 & 2.1 \\
\hline \multicolumn{8}{|c|}{ Region D } \\
\hline 22 & IGKV1-5 protein & 117 & 5 & IPI00430820 & 5.7 & 26 & 4.2 \\
\hline 32 & $\begin{array}{l}\text { Putative uncharacterized } \\
\text { protein }\end{array}$ & 64 & 3 & IPI00785200 & 7.6 & 25.4 & 3.8 \\
\hline 34 & IGL@ protein & 70 & 2 & IPI00154742 & 5.9 & 25.1 & 3.7 \\
\hline 41 & Not identified & & & & 6.1 & 24.7 & 3.2 \\
\hline 50 & Ig $\kappa$ chain $V-I$ region WEA & 91 & 1 & IPI00003469 & 9.1 & 11.9 & 2.8 \\
\hline $58 / 215$ & IGKV1-5 protein & $171 / 171$ & $3 / 3$ & IPI00419424 & 6.3 & 26.5 & $2.9 / 3.4$ \\
\hline 63 & Ig $\kappa$ chain V-II region MIL & 67 & 1 & IPI00387110 & 9.4 & 12.2 & 3.0 \\
\hline 136 & $\begin{array}{l}\text { Putative uncharacterized } \\
\text { protein }\end{array}$ & 64 & 3 & IPI00785200 & 7.6 & 25.4 & 5.3 \\
\hline 249 & $\lg \kappa$ chain V-IV region Len & 72 & 1 & IPI00387120 & 7.9 & 12.7 & 3.2 \\
\hline 277 & Ig $\kappa$ chain $V-I$ region EU & 49 & 1 & IPI00387026 & 8.6 & 11.9 & 3.4 \\
\hline 285 & IGKC protein & 48 & 4 & IPI00430808 & 6.2 & 25.9 & 2.9 \\
\hline 286 & IGLV4-3 & 41 & 2 & IPI00382938 & 6.3 & 26.3 & 2.4 \\
\hline
\end{tabular}

Spot trypsin digests were identified using nanoflow HPLC-MS/MS, correlated to compiled peptide data (Matrix Science), with a high degree of confidence $(p \leq 0.05)$. Glycogen phosphorylase $\mathrm{b}$ was a positive control spot picked from the 2-DE molecular weight marker. 


\subsection{Expression of disease-associated proteins in CICs}

To characterize potential disease-associated proteins within the CICs of CE and EOA groups, the protein expression data from these two groups were combined to identify common spots that are subsequently absent in the combined MR and healthy control group. A series of 37 potential diseaseassociated CIC proteins were expressed at a two-fold or higher level than could be detected in CICs from the MR and healthy combined control group (Fig. 2). The majority of these putative disease-associated proteins were located within four distinct regions, as defined by similar mobility/ charge (Fig. 3). Alternatively, 45 proteins had a two-fold or greater decrease in their intensity levels as compared with the MR and healthy combined control group. Hierarchal cluster analysis confirmed potential disease-associated proteins by identifying highly similar inter-individual protein expression patterns (Fig. 4). Resulting heat maps and dendrograms revealed interesting trends of increased protein expression that were common to the combined disease group and decreased or absent in the combined control group. Proteins with a statistically significant $(p \leq 0.05)$ increase in their expression and their identities are listed in Table 2.

Twenty-eight of the 37 potential disease-associated proteins, with sufficient yields from trypsin digests, were identified by nanoflow HPLC-MS/MS, followed by searching the IPI human and NCBInr databases with a high degree of confidence $(p \leq 0.05)$. The proteins spots were numbered by the image analysis software and shown in Figs. 2 and 3. The majority of these proteins characterized as Ig heavy and light chains. Spots 229, 295, and 311 were identified as isoforms of serum albumin. Spots 276 and $218 / 244$ were identified as serotransferrin precursor and alpha-1-antitrypsin $(\alpha-1 \mathrm{AT})$ precursor with 2.7- and 3.5/3.1fold increased expression, respectively. Spot 144, 174, 203, and 230 were identified as isoforms of glyceraldehyde-3phosphate dehydrogenase (GAPDH) with 3.5-, 3.2-, 2.9-, and 2.4-fold increased expression, respectively. Spot 32 and 136 were identified as putative uncharacterized proteins with 3.8- and 5.3-fold overexpression, respectively. Additionally, spot 240 was identified as an uncharacterized IgG heavy chain protein with a 2.7-fold increased expression. Spot 224 was excluded from this analysis as the protein concentration was insufficient.

\section{Discussion}

As previously stated, JIA is a heterogenous group of diseases with variable clinical presentations and long-term physical outcomes. Laboratory markers are limited and usually derived from peripheral whole blood. Dysregulation of immune function is a hallmark of the disease, involving altered humoral, cell-mediated, and innate responses. In light of this, a role for pathogenic CICs has been established [3, 8-17]. In many IC-mediated diseases either the offending antigen is unknown or multiple candidate antigens have been implicated. Identifying disease-associated proteins in CICs, or related posttranslational modifications, could have potential diagnostic utility by recognizing aggressive disease early in its course and providing an important window for therapeutic intervention.

Several putative disease markers have been identified in the SF of chronic adult RA and spondyloarthropathy, including: calgranulins $\mathrm{A}, \mathrm{B}$, and $\mathrm{C}$, fibrinogen $\beta$-chain, fructose bisphosphate aldolase A, and $\alpha$-enolase [29]. Additionally, serum amyloid A was found to be increased in both the serum and SF of adult RA patients. Other disease markers, including C-reactive protein and haptoglobin have been correlated with a chronic inflammatory adult RA $[29,44,45]$. However, few studies have been done to identify proteins associated with disease in JIA [28, 46-48]. Recently, Gibson et al. [28] identified collagen X and T-cell receptor $\alpha \beta$ fragments at significantly higher levels within SF of patients suffering from recurrent episodes of inflammation. Likewise, Rosenkranz et al. [48] characterized protein expression in the SF of the three most common subtypes of JIA. Among the proteins identified with differential expression patterns were precursors for $\alpha$-1-antichymotrypsin, and serotransferrin, and Igא chain C. Some findings presented in the present work, including $\alpha-1 \mathrm{AT}$, serotransferrin, and Igא chain $\mathrm{C}$, are homologous to these proteins.

The proteins that comprise CICs are ideal targets as elevated levels of CICs represent a pathologic overflow and parallel activity of the arthritis and systemic features $[9,18$, 49-52]. Modern proteomic technologies, such as 2-DE combined with MS, afford the ability to efficiently characterize protein profiles within CICs. One of the proteins identified in this study, GAPDH, is a classic metabolic enzyme involved in glycolysis and energy production. However, numerous studies established that it is a multifunctional protein involved in DNA processing, apoptosis, and transferrin transport $[53,54]$. Cytosolic GAPDH has a $\mathrm{pI}$ of 7.0-7.5, whereas nuclear GAPDH has a $\mathrm{pI}$ of 8.7 [53]. Thus, posttranslational modifications (i.e. phosphorylation) may be involved in the multiple functions of GAPDH. Moreover, oxidative stress induces nitric oxide-mediated S-nitrosylation of GAPDH and its subsequent nuclear translocation to mediate tumor necrosis factor (TNF)-related apoptosis inducing ligand-induced cell death [55]. Interestingly, TNF-related apoptosis inducing ligand has been implicated in the proliferation of synovial fibroblasts that contribute to the joint pathology seen in adult RA [56].

Of particular relevance to this study, the antigenicity of GAPDH and its role as a potential autoantigen has been investigated [57]. GAPDH has been implicated as a component of the proliferating cell nuclear antigen (PCNA) in SLE. Specifically, a $37 \mathrm{kDa}$ protein $(\mathrm{p} I$ 8.5) component of the PCNA complex reacted with antibodies from SLE sera and was identified as GAPDH. Serum PCNA levels, which 
may be crucial for antigen presentation, are significantly elevated in SLE patients who are positive for these antibodies. Importantly, PCNA complexes are released into peripheral blood with other nuclear antigen whenever activated cells are killed by apoptosis. Other work has identified anti-GAPDH antibodies in diseases such as multiple sclerosis and glaucoma, which is believed to have an autoimmune component [58, 59]. Further study has shown significantly increased copies of GAPDH DNA in the serum and plasma of RA patients indicative of increased cell death [60].

Interestingly, a number of glycolytic enzymes have been implicated in adult RA, related spondyloarthropathies, and the corresponding $\mathrm{K} / \mathrm{BxN}$ murine arthritis model. As previously mentioned, fructose bisphosphate aldolase A and $\alpha$-enolase were shown to be overexpressed in the inflamed synovium of patients with spondyloarthropathy [29]. Previous studies have confirmed antibodies reactive to either of these glycolytic enzymes in the sera of patient's adult RA [61-63]. Likewise, autoantibodies targeting triosephosphate isomerase have also been identified in RA serum and SF, albeit at lower sensitivities [29]. In the K/BxN murine model of RA, glucose-6-phosphate isomerase (GPI)-anti-GPI immune complexes are necessary for and integral to disease pathophysiology [64, 65]. While inconclusive, anti-GPI antibodies have also been identified in the sera and SF of patients with adult RA, and to a lesser degree in JIA [66-69]. Some studies link the presence of these antibodies to disease with an aggressive phenotype or extra-articular manifestations. In our patient cohort, expression of GAPDH was up to 3.5-fold higher in CICs of the combined disease group as compared with the combined control group. With a $\mathrm{pI}$ of 8.6, the identified protein is most likely nuclear GAPDH. Taken together, these findings suggest that GAPDH should be considered a disease-associated protein of interest. Additional analysis of GAPDH within CICs may shed light on a potential mechanism in autoimmune responses.

In addition to GAPDH, a precursor to serotransferrin was also significantly overexpressed in the CICs of the combined disease group. Most extracellular $\mathrm{Fe}^{2+}$ in the plasma is bound to transferrin. Immune cells require $\mathrm{Fe}^{2+}$ for activation, proliferation, and maturation [70]. Likewise, $\mathrm{Fe}^{2+}$ is essential for the production of highly toxic hydroxyl radicals that mediate macrophage-mediated cytoxicity. Of potential importance, GAPDH has recently been shown to function as a novel transferrin receptor on macrophages [54]. These new findings suggest that the interaction between GAPDH and transferrin might determine how they are associated with the disease process. Other studies have confirmed an upregulation of serum transferrin and ferritin in active JIA disease [71-74]. Taken together, these findings suggest that the interaction of $\mathrm{Fe}^{2+}$-bound transferrin with GAPDH could reveal cryptic epitopes in both transferrin and GAPDH. Furthermore, the enhanced transport of $\mathrm{Fe}^{2+}$ by both GAPDH and natural resistance-associated macro- phage protein 1 could directly contribute to the pathogenesis that leads to joint destruction.

In addition to transferrin, serum $\alpha-1 \mathrm{AT}$ has been linked to active JIA [73]. As an acute-phase protein, $\alpha-1 \mathrm{AT}$ is a serine protease inhibitor with a variety of functions. A relevant function to this study regards $\alpha-1 \mathrm{AT}$ as an anti-inflammatory molecule and regulator of the immune response. Key features include the inhibition of antibody-dependent cellmediated cytotoxicity, and the cytoxicity mediated by $\mathrm{T}$ cells, natural killer cells, neutrophils, and monocytes [75, 76]. Regulation of innate immunity is also attributed to $\alpha-1 \mathrm{AT}$. By controlling CD14 expression, $\alpha-1 \mathrm{AT}$ inhibits lipopolysaccharide-induced proinflammatory cytokines TNF- $\alpha$, interleukin-1 $\beta$, and interleukin-8 [77]. Another study has shown a role for $\alpha-1 \mathrm{AT}$ in the inhibition of two key molecules involved in joint destruction, matrix metalloproteinase, and TNF- $\alpha$ [78]. Subsequently, a lack of $\alpha$-1AT in adult RA correlates with more tissue destruction [79-81]. In this study, $\alpha$-1AT precursor was expressed up to 3.5 -fold greater levels in CICs from the combined disease group as compared with the combined control group. Further work is required to determine the role of $\alpha-1 \mathrm{AT}$ as a disease-associated protein and what could transpire due to its presence in CICs.

Of the remaining identified proteins, three uncharacterized proteins were overexpressed 2.7-, 3.8-, and 5.3-fold, respectively. Likewise, a number of immunoglobulin heavy and light chains were overexpressed up to 4.2-fold in CICs from the disease group. The increased expression of immunoglobulin in the disease groups, as compared with the MR and healthy controls, is not surprising as there is increased B cell activity that is paramount to the disease process. This activity results in an overproduction of disease-associated immunoglobulin, or autoantibodies, that contribute to CIC formation. The varying mobility observed among the light chains, in particular, would suggest a number of potential posttranslational modifications such as the addition of sugar moieties. Further analysis is required to determine potential posttranslational modifications or other characteristics of these proteins that associate them with the disease process in JIA. While five of the identified proteins had only one peptide matched, their MS/MS spectra were confident and they did share sequence homology with other proteins identified within this study. In light of these relationships, further analysis is required to establish the importance of these proteins. Protein spots 23, 165, 176, 194, 211, 247, and 309 had insufficient protein yields to be definitively identified. The protein loading and sensitivity of the 2-DE technique need to be improved. To the best of our knowledge, this is the first study to characterize the CIC proteome from patients with JIA. These findings suggest a set of diseaseassociated proteins linked to a destructive disease course. Peptide profiles could be used to differentiate disease subgroups to predict patients who are more likely to suffer from severe disease. Moreover, "proteome records" from patient CICs showing disease-associated changes over time may allow tracking and refinement of therapeutic responses in a given individual [29]. These "records" may serve as sentinels 
of joint damage, which can occur in patients suffering an insidious disease. Additional analysis of these proteins should give insight into the multifaceted mechanisms that contribute to the etiology or maintenance of the disease process seen in aggressive forms of JIA.

Funding was provided by the Campbell-Avery Charitable Trust, the Dorr Family Charitable Trust, and the Lupus/Juvenile Arthritis Research Group of Saint Louis.

J. M. Low, D. S. Gibson, M. Zhu, S. Chen, M. E. Rooney, M. J. Ombrello, and T. L. Moore have no conflict of interest and A.K. Chauhan has financial interest in ProGen Biologics, $L L C$.

\section{References}

[1] Moore, T. L., in: Rakel, R. E., Bope, E. T. (Eds.), Conn's Current Therapy 2009, Elsevier Saunders, Philadelphia 2009, pp. 983-986.

[2] Ravelli, A., Martini, A., Juvenile idiopathic arthritis. Lancet 2007, 369:767-778.

[3] Cassidy, J. T., Petty, R. E., in: Cassidy, J. T., Petty, R. E., Laxer, R. M., Lindsley, C. B. (Eds.), Textbook of Pediatric Rheumatology, 5th Edn., Elsevier Saunders, Philadelphia 2005, pp. 206-300.

[4] Zak, M., Pederson, F. K., Juvenile chronic arthritis into adulthood: a long-term follow-up study. Rheumatology 2000, 39, 198-204.

[5] Ravelli, A., Martini, A., Early predictors of outcome in juvenile idiopathic arthritis. Clin. Exp. Rheumatol. 2003, 21, S89-S93.

[6] Oen, K., Long-term outcomes and predictors for patients with juvenile idiopathic arthritis. Best Prac. Res. Clin. Rheumatol. 2002, 16, 347-360.

[7] Clemens, L. E., Albert, E., Ansell, B. M., HLA studies in IgM rheumatoid factor positive childhood arthritis. Ann. Rheum. Dis. 1983, 42, 431-434.

[8] Moore, T. L., Osborn, T. G., Nesher, G., Immune complexes from sera of patients with juvenile rheumatoid arthritis reveal novel 40 and $60 \mathrm{kD}$ bands. Clin. Exp. Rheumatol. 1995, 13, 667-672.

[9] Jarvis, J. N., Pathogenesis and mechanisms of inflammation in the childhood rheumatic diseases. Curr. Opin. Rheumatol. 1998, 10, 459-467.

[10] Moore, T. L., Sheridan, P. W., Traycoff, R. B., Zuckner, J., Dorner, R. W., Immune complexes in juvenile rheumatoid arthritis: a comparison of four methods. J. Rheumatol. 1982, 9, 395-401.

[11] Khalkhali-Ellis, Z., Bulla, G. A., Schlesinger, L. S., Kirschmann, D. A. et al., C1q-containing immune complexes purified from sera of juvenile rheumatoid arthritis patients mediate IL-8 production by human synoviocytes: role of C1q receptors. J. Immunol. 1999, 163, 4612-4620.

[12] Jarvis, J. N., Wang, W., Moore, H. T., Zhao, L., Xu, C. S., In vitro induction of proinflammatory cytokine secretion by juvenile rheumatoid arthritis synovial fluid immune complexes. Arthritis Rheum. 1997, 40, 2039-2046.

[13] Moore, T. L., Dorner, R. W., Separation and characterization of complement-fixing immune complexes in juvenile rheumatoid arthritis patients. Rheumatol. Int. 1986, 6, 49-52.

[14] Moore, T. L., Sheridan, P. W., Zuckner, J., Dorner, R. W., Separation and characterization of immune complexes containing 19S IgM rheumatoid factor-IgG in juvenile arthritis. Arthritis Rheum. 1983, 26, 165-169.

[15] Moore, T. L., Dorner, R. W., Sheridan, P. W., Zuckner, J., Precipitation of $19 S \operatorname{IgM}$ rheumatoid factor IgG circulating immune complexes in patients with juvenile rheumatoid arthritis by polyethylene glycol and separation by immobilized protein A. Clin. Exp. Immunol. 1984, 56, 247-252.

[16] Moore, T. L., Osborn, T. G., Dorner, R. W., 19S IgM rheumatoid factor-7S IgG rheumatoid factor immune complexes isolated in sera of patients with juvenile rheumatoid arthritis. Pediatr. Res. 1986, 20, 977-981.

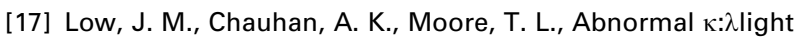
chain ratio in circulating immune complexes as a marker for B cell activity in juvenile idiopathic arthritis. Scan. J. Immunol. 2007, 65, 76-83.

[18] Nydegger, U. E., in: Harris, E. D., Budd, R. C., Firestein, G. S., Genovese, M. C. (Eds.). Kelley's Textbook of Rheumatology, 7th Edn., Elsevier Saunders, Philadelphia 2005, pp. 332-341.

[19] Melsom, R. D., Smith, P. R., Maini, R. N., Demonstration of an unidentified $48 \mathrm{kD}$ polypeptide in circulating immune complexes in rheumatoid arthritis. Ann. Rheum. Dis. 1987, 46, 104-109.

[20] Mary, C., Ange, G., Dunan, S., Lamouroux, D., Quilici, M., Characterization of a circulating antigen involved in immune complexes in visceral leishmaniasis patients. Am. J. Trop. Med. Hyg. 1993, 49, 492-501.

[21] Madan, T., Banerjee, B., Bhatnagar, P. K., Shah, A., Sarma, P. U., Identification of $45 \mathrm{kD}$ antigen in immune complexes of patients of allergic bronchopulmonary aspergillosis. Mol. Cell Biochem. 1997, 166, 111-116.

[22] Zhong, W., Oschmann, P., Wellensiek, H. J., Detection and preliminary characterization of circulating immune complexes in patients with Lyme disease. Med. Microbiol. Immunol. 1997, 186, 153-158.

[23] Rojas, R. E., Segal-Eiras, A., Characterization of circulating immune complexes in leprosy patients and their correlation with specific antibodies against Mycobacterium leprae. Clin. Exp. Dermatol. 1997, 22, 223-229.

[24] Golda, R., Wolski, Z., Wyzomirska-Golda, M., Madalinski, K., Michalkiewcz, J., The presence and structure of circulating immune complexes in patients with prostate tumors. Med. Sci. Monit. 2004, 10, CR123-CR127.

[25] Procaccia, S., Lanzanova, D., Caputo, D., Ferrante, P. et al., Circulating immune complexes in serum and in cerebrospinal fluid of patients with multiple sclerosis. Characterization and correlation with the clinical course. Acta Neurol. Scand. 1988, 77, 373-381.

[26] Pagetta, A., Trementozzi, E., Corbetti, L., Frasson, M. et al., Characterization of immune complexes of idiotypic catalytic 
and anti-idiotypic antibodies in plasma of type 1 diabetic subjects. Mol. Immunol. 2007, 44, 2870-2883.

[27] Hoffman, W. L., Kelly, P. J., Ruggles, A. O., Characterization of immune complex components by dot blot analysis. Anal. Biochem. 1992, 207, 44-50.

[28] Gibson, D. S., Blelock, S., Brockbank, S., Curry, J. et al., Proteomic analysis of recurrent joint inflammation in juvenile idiopathic arthritis. J. Proteome Res. 2006, 5, 1988-1995.

[29] Gibson, D. S., Rooney, M. E., The human synovial fluid proteome: a key factor in the pathology of joint disease. Proteomics Clin. Appl. 2007, 1, 889-899.

[30] Park, M. R., Wang, E. H., Jin, D. C., Cha, J. H. et al., Establishment of a 2-D human urinary proteomic map in IgA nephropathy. Proteomics 2006, 6, 1066-1076.

[31] Kim, C. W., Cho, E. H., Lee, Y. J., Kim, Y. H. et al., Diseasespecific proteins from rheumatoid arthritis patients. J. Korean Med. Sci. 2006, 21, 478-484.

[32] Gobezie, R., Kho, A., Krastins, B., Sarracino, D. A. et al., High abundance synovial fluid proteome: distinct profiles in health and osteoarthritis. Arthritis Res. Ther. 2007, 9, R36.

[33] Kennedy, S., Proteomic profiling from human samples: the body fluid alternative. Toxicol. Lett. 2001, 120, 379-384.

[34] de Seny, D., Fillet, M., Meuwis, M. A., Geurts, P. et al., Discovery of new rheumatoid arthritis biomarkers using the surface-enhanced laser desorption/ionization time-of-flight mass spectrometry ProteinChip approach. Arthritis Rheum. 2005, 52, 3801-3812.

[35] Coombes, K. R., Morris, J. S., Hu, J., Edmondson, S. R., Baggerly, K. A., Serum proteomics profiling-a young technology begins to mature. Nat. Biotechnol. 2005, 23, 291-292.

[36] Diamandis, E. P., Mass spectrometry as a diagnostic and a cancer biomarker discovery tool: opportunities and potential limitations. Mol. Cell. Proteomics 2004, 3, 367-378.

[37] Pan, S., Zhang, H., Rush, J., Eng, J. et al., High throughput proteome screening for biomarker detection. Mol. Cell. Proteomics 2005, 4, 182-190.

[38] Hueber, W., Robinson, W. H., Proteomic biomarkers for autoimmune disease. Proteomics 2006, 6, 4100-4105.

[39] Wang, R., Chait, B. T., High-accuracy mass measurement as a tool for studying proteins. Curr. Opin. Biotechnol. 1994, 5, 77-84.

[40] Chauhan, A. K., Moore, T. L., Presence of plasma complement regulatory proteins clusterin (Apo $\mathrm{J}$ ) and vitronectin (S40) on circulating immune complexes (CIC). Clin. Exp. Immunol. 2006, 145, 398-406.

[41] Chen, S., Rapid protein identification using direct infusion nanoelectrospray ionization mass spectrometry. Proteomics 2006, 6, 16-25.

[42] Sheffield, J., Taylor, N., Fauquet, C., Chen, S., Cassava root proteome: protein identification and differential expression. Proteomics 2006, 6, 1588-1598.

[43] Kersey, P. J., Duarte, J., Williams, A., Karavidopoulou, Y. et al., The International Protein Index: an integrated data- base for proteomics experiments. Proteomics 2004, 4, 1985-1988.

[44] Kantor, A. B., Wang, W., Lin, H., Govindarajan, H. et al., Biomarker discovery by comprehensive phenotyping for autoimmune diseases. Clin. Immunol. 2004, 111, 186-195.

[45] Kuhn, E., Wu, J., Karl, J., Liao, H. et al., Quantification of Creactive protein in the serum of patients with rheumatoid arthritis using multiple reaction monitoring mass spectrometry and 13C-labeled peptide standards. Proteomics 2004, 4, 1175-1186.

[46] Low, J. M., Chauhan, A. K., Moore, T. L., Circulating immune complexes from juvenile idiopathic arthritis patients reveal disease-specific proteins. Arthritis Rheum. 2006, 54, S691.

[47] Low, J. M., Chauhan, A. K., Gibson, D. S., Rooney, M. E., Moore, T. L., Characterization of protein expression profiles in circulating immune complexes from juvenile idiopathic arthritis. Arthritis Rheum. 2007, 56, S672.

[48] Rosenkranz, M. E., Giles, B., Reynolds, P. R., Wilson, D. C. et al., Synovial fluid proteins differentiate between subtypes of juvenile idiopathic arthritis. Arthritis Rheum. 2007, 56, S672.

[49] Schifferli, J. A., Taylor, R. P., Physiological and pathological aspects of circulating immune complexes. Kidney Int. 1989, 35, 993-1003.

[50] Rossen, R. D., Brewer, E. J., Person, D. A., Templeton, J. W., Lidsky, M. D., Circulating immune complexes and antinuclear antibodies in juvenile rheumatoid arthritis. Arthritis Rheum. 1977, 20, 1485-1490.

[51] Moran, H., Hansell, B. M., Mowbray, J. F., Levinsky, R. J., Soothill, J. F., Antigen-antibody complexes in the serum of patients with juvenile chronic arthritis. Arch. Dis. Child $1979,54,120-122$.

[52] Nydegger, U. E., Immune complex pathophysiology. Ann. N Y Acad. Sci. 2007, 1109, 66-83.

[53] Sirover, M. A., New nuclear functions of the glycolytic protein, glyceraldehydes-3-phosphate dehydrogenase, in mammalian cells. J. Cell. Biochem. 2005, 95, 45-52.

[54] Raje, C. I., Kumar, S., Harle, A., Nanda, J. S., Raje, M., The macrophage cell surface glyceraldehydes-3-phosphate dehydrogenase is a novel transferrin receptor. J. Biol. Chem. 2007, 282, 3252-3261.

[55] Du, Z. X., Wang, H. Q., Zhang, H. Y., Gao, D. X., Involvement of glyceraldehydes-3-phosphate dehydrogenase in tumor necrosis factor-related apoptosis-inducing ligand-mediated death of thyroid cancer cells. Endocrinology 2007, 148, 4352-4361.

[56] Morel, J., Audo, R., Hahne, M., Combe, B., Tumor necrosis factor-related apoptosis-inducing ligand (TRAIL) induces rheumatoid arthritis synovial fibroblast proliferation through mitogen-activated protein kinases and phosphatidylinositol 3-kinase/Akt. J. Biol. Chem. 2005, 280, 15709-15718.

[57] Takasaki, Y., Kaneda, K., Matsushita, M., Yamada, H. et al., Glyceraldehyde-3-phosphate dehydrogenase is a novel autoantigen leading autoimmune responses to proliferating cell nuclear antigen multiprotein complexes in lupus patients. Int. Immunol. 2004, 16, 1296-1304. 
[58] Joachim, S. C., Wuenschig, D., Pfeiffer, N., Grus, F. H., IgG antibody patterns in aqueous humor of patients with primary open angle glaucoma and pseudoexfoliation glaucoma. Mol. Vis. 2007, 13, 1573-1579.

[59] Kolln, J., Ren, H. M., Da, R. R., Zhang, Y. et al., Triosephosphate isomerase- and glyceraldehydes-3-phosphate dehydrogenase-reactive autoantibodies in the cerebrospinal fluid of patients with multiple sclerosis. J. Immunol. 2006, 177, 5652-5658.

[60] Zhong, X. Y., von Muhlenen, I., Li, Y., Kang, A. et al., Increased concentrations of antibody-bound circulatory cell-free DNA in rheumatoid arthritis. Clin. Chem. 2007, 53, 1609-1614.

[61] Kinloch, A., Tatzer, V., Wait, R., Peston, D. et al., Identification of citrullinated alpha-enolase as a candidate autoantigen in rheumatoid arthritis. Arthritis Res. Ther. 2005, 7, R1421-R1429.

[62] Saulot, V., Vittecoq, O., Charlionet, R., Fardellone, P. et al., Presence of autoantibodies to the glycolytic enzyme alphaenolase in sera from patients with early rheumatoid arthritis. Arthritis Rheum. 2002, 46, 1196-1201.

[63] Ukaji, F., Kitajima, I., Kubo, T., Shimizu, C. et al., Serum samples of patients with rheumatoid arthritis contain a specific autoantibody to "denatured" aldolase A in the osteoblast-like cell line, MG-63. Ann. Rheum. Dis. 1999, 58, 169-174.

[64] Mandik-Nayak, L., Allen, P. M., Initiation of an autoimmune response: insights from a transgenic model of rheumatoid arthritis. Immunol. Res. 2005, 32, 5-13.

[65] Ji, H., Ohmura, K., Mahmood, U., Lee, D. M. et al., Arthritis critically dependent on innate immune system players. Immunity 2002, 16, 157-168.

[66] Schaller, M., Stohl, W., Tan, S. M., Benoit, V. M. et al., Raised levels of anti-glucose-6-phosphate isomerase IgG in serum and synovial fluid from patients with inflammatory arthritis. Ann. Rheum. Dis. 2005, 64, 743-749.

[67] Muraki, Y., Matsumoto, I., Chino, Y., Hayashi, T. et al., Glucose-6-phosphate isomerase variants play a key role in the generation of anti-GPI antibodies: possible mechanism of autoantibody production. Biochem. Biophys. Res. Commun. 2004, 323, 518-522.

[68] Schepp, C. P., Dannecker, L., Haug, M., Kummerle-Deschner, J. et al., Autoantibodies in juvenile idiopathic arthritis: glucose-6-phosphate isomerase is not a specific target. J. Rheumatol. 2004, 31, 1630-1638.
[69] van Gaalen, F. A., Toes, R. E., Ditzel, H. J., Schaller, M. et al., Association of autoantibodies to glucose-6-phosphate isomerase with extraarticular complications in rheumatoid arthritis. Arthritis Rheum. 2004, 50, 395-399.

[70] Bowlus, C. L., The role of iron in T cell development and autoimmunity. Autoimmun. Rev. 2003, 2, 73-78.

[71] Fall, N., Barnes, M., Thornton, S., Luyrink, L. et al., Gene expression profiling of peripheral blood from patients with untreated new-onset systemic juvenile idiopathic arthritis reveals molecular heterogeneity that may predict macrophage activation syndrome. Arthritis Rheum. 2007, 56, 3793-3804.

[72] Craft, A. W., Eastham, E. J., Bell, J. I., Brigham, K., Serum ferritin in juvenile chronic polyarthritis. Ann. Rheum. Dis. 1977, 36, 271-273.

[73] Nagy, K., Kassay, L., Velkey, L., Measurement of the inflammatory activity by the help of serum acute-phase proteins in juvenile chronic arthritis. Acta Univ. Carol. Med. 1991, 37, 41-45.

[74] Kirel, B., Yetgin, S., Saatci, U., Ozen, S. et al., Anaemia in juvenile chronic arthritis. Clin. Rheumatol. 1996, 15, 236-241.

[75] Janciauskiene, S. M., Nita, I. M., Stevens, T., $\propto 1$-Antitrypsin, old dog, new tricks; $\alpha 1$-antitrypsin exerts in vitro anti-inflammatory activity activity in human monocytes by elevating cAMP. J. Biol. Chem. 2007, 282, 8573-8582.

[76] Breit, S. N., Wakefield, D., Robinson, J. P., Luckhorst, E. et al., The role of $\alpha 1$-antitrypsin deficiency in the pathogenesis of immune disorders. Clin. Immunol. Immunopathol. 1985, 35, 363-380.

[77] Nita, I. M., Serapinas, D., Janciauskiene, S. M., $\alpha 1$-Antitrypsin regulates $\mathrm{CD} 14$ expression and soluble CD14 levels in human monocytes in vitro. Int. J. Biochem. Cell. Biol. 2007, 39, 1165-1176.

[78] Churg, A., Wang, X., Wang, R. D., Meixner, S. C. et al., $\alpha 1$ Antitrypsin suppresses TNF- $\alpha 1$ and MMP-12 production by cigarette smoke-stimulated macrophages. Am. J. Respir. Cell. Mol. Biol. 2007, 37, 144-151.

[79] Cox, D. W., Huber, O., Rheumatoid arthritis and $\alpha 1$-antitrypsin. Lancet 1976, 1, 1216-1217.

[80] Swedlund, H. A., Hunder, G. W., Gleich, G. J., $\alpha 1$-Antitrypsin in serum and synovial fluid in rheumatoid arthritis. Ann. Rheum. Dis. 1974, 33, 162-164.

[81] Breit, S. N., Robinson, J. P., Penny, R., The effect of $\alpha 1$ antitrypsin on phagocyte function. J. Clin. Lab. Immunol. $1983,10,147-149$. 